\title{
STUDENTS E-READINESS IN INSTITUTIONS OF THE Royal COMMISSION IN JUBAIL
}

\author{
Saleh Alzahrani ${ }^{1}$ and Mohamed Elsaadani ${ }^{2}$ \\ ${ }^{1 \& 2}$ Assistant Professor, Jubail University College, Royal Commission in Jubail, Jubail \\ Industrial City, Kingdom of Saudi Arabia. \\ ${ }^{1}$ Assistant Professor, the Arab Academy for Science \& Technology \& Maritime \\ Transport, Alexandria, Egypt.
}

\begin{abstract}
Information and communication technologies (ICTs) provide a rich integrated educational environment, which capable of changing the lives of students. The purpose of this research paper is to investigating ereadiness of the students in the affiliate Institutions of the Royal Commission in Jubail, and whether their experience in using ICTs influences their judgement towards ICTs, and whether their judgement and experience toward ICTs influence their use of ICTs or not. Survey methodology is facilitated through the use of the questionnaires. Survey domain is a random sampling of studentsin Institutions of the Royal Commission of Jubail. With a 95\% confidence level of a possible sample frame of 669, the study sampled 1032 respondents (15\%). Results showed that students'judgement towards ICTs is highly positive, which reflect their e-readiness and willingness to use ICTs, but the analysis showed that the experience with ICTs did not significantly predict students'judgement about ICTs use. It was discovered that the following set of ICTs requires the most attention in the future adoption planning by the Royal Commission for its three affiliate Higher education institutions (HEIs): "Blackboard", "smart devices", "e-bulletin boards", and "e-materials". This set of ICTs receives the least scores of use and experience responses from study participants.The result of this study provides valuable insights into students' e-readiness. This information may be used to develop and support factors that enhance strategies for adopting ICTs by students.
\end{abstract}

\section{KEYWORDS}

e-readiness, ICTs, JUC, JIC, JTI, judgment, Royal Commission of Jubail, HEI

\section{INTRODUCTION}

Researchers have come to an apparent conclusion that the adoption of ICTs creates a competitive advantage, as it is obvious that global advancements in ICTs have led to the emergence of global economies driven by knowledge [1]. Involvement in these global economies needs organizations to be e-ready in order to harness various digital opportunities [2]. Moreover, it is mandatory in the current information era not to neglect the powerful component of ICTs in the education field. ICTs already caused major positive changes to the eLearning field [3]. 
It was reported that the most common obstacle for HEIs in adopting ICTs is establishing the environment that supports the effective use of ICTs [4]. Moreover, it was reported that there are some other aspects that may delay the overall success of ICTs adoption, such as institutional, social and economic factors [5].

The demand for e-learning approaches is currently advancing along with the advancement in various ICTs [6]. These advancements will pave way for the use of ICTs in teaching and learning, but this requires a special preparation for HEIs students [7, 8].

Many HEIs are rapidly adopting recent ICTs, especially e-learning platforms in order to gain competitive advantages [9, 10], as well as to ensure the reduction of the space and time boundaries in their activities to increase the interaction between HEIs stakeholders $[11,12]$.

It was noted that $[13,14]$ has declared that assessing students e-readiness especially in Business study is a more promising area of evaluation, as research stream regarding e-learning has much been done, but the investigation into e-readiness of the users themselves has been very little. This represents one major motive to accomplish that research on hand, which will contribute to theory and practice by proposing a context-aware conceptual framework for appropriate measurement of e-readiness in a developing world HEIs context[15].

\section{ICTS IN HEIS}

Using ICTs in teaching and learning has become a well-known and common phenomenon in higher education [16]. As the use of ICTs is increasing worldwide, ICTs have changed lives in general than it was before, and as a consequence changed HEIs dramatically. ICTs provide HEIs with a new educational environment that is capable of changing lives of both faculty and students [17], as well as enhancing speed and quality of teaching and learning process [18].

Educational technologies are becoming more and more prevalent in the education management. ICTs have changed HEIs to become more space and time flexible than traditional modes of study; increasing the accessibility, flexibility, and choices for interactivity. Using ICTs in education has overcome the historical limitations of traditional teaching and learning environments; thus enhancing education profession to be more interactive, challenging, and situated[19].

HEIs utilizes ICTs in three different methodologies. They can use ICTs in delivering online education, or they can enhance traditional teaching by mixing it with e-learning technologies, such as using "blended" teaching methodology, or they can supplement traditional teaching with e-learning technologies, such as using LMSs as a repository for course materials [20].

\section{STUDENTS E-READINESS}

E-learning initiatives are mandatory in order to offer alternatives to students other than traditional mode of learning as it is considered as a solution to demand increasing for higher education, as well as to enable countries to become more competitive [21]. 
International Journal of Advanced Information Technology (IJAIT) Vol. 8, No.4/5, October 2018

In different studies conducted by various authors [22, 23, 24, 25, 26], they revealed that there was a low acceptance of e-learning initiatives, which was due to low awareness of technologies, computer illiteracy, and the fear of isolation as a result of using the technologies.These studies presents a challenge that foster researchers to pursue the research at hand.

\section{RESEARCH OBJECTIVE}

This research complements a previous conducted research that aimed at assessing faculty ereadiness. An interest in this topic developed as a result of personal observation of several failures and the loss of interest in ICT implementation by major number ofstudents.

Current research aims at investigating e-readiness of the students in the affiliate Institutions of the Royal Commission in Jubail - Jubail University College (JUC), Jubail Industrial College (JIC), and Jubail Technical Institute (JTI) - and whether their experience in using ICTs influences their judgementtowards ICTs, and whether their judgement and experience toward ICTs influence their

use of ICTs or not. Current research results will aid HEIs in promoting ICTs in teaching and learning, moreover, it will aid in preparing a more qualified and skilled graduates.

\section{MeThodology}

This paper draws on the academic year 2017-2018 at HEIs of the Royal Commission in Jubail. In the context of this research, e-readiness involves the ability and capacity of JUC, JIC, and JTI students to integrate ICTs in their academic activities.

As there is no need to control studentsbehavioural activities, and due to focusing only on current events for adopting ICTs, thus, the appropriate research strategy is to use the survey, which was conducted to determine:

1. What relationships exist between students' demographics (i.e., studying institution, age, studying department, accessibility to computer and internet at HEIs and at home, and finally, training hours received related to using ICTs for education purposes) and the main survey constructs?

2. What experiences in ICTs does students had?

3. To what extent do studentsuse ICTs in their studying and learning activities?

4. What judgement do studentshave towards using ICTs in their studying and learningactivities?

The instrument was tested in order to ensure that the questions used reflect the intended meaning of the researchers and to ensure that this meaning will be understood by anyone reading these questions, thus increasing instrument validity.

The instrument was piloted in two distinct ways. First, as part of the design and validation of the instrument, a pilot version of the instrument was sent to 15 faculty members in JUC, JIC, and JTI, who were experienced in research as well as teaching and were known to be significantly involved in using ICTs in their teaching, moreover, it was sent to 15 studentsfrom major years. This proved to be a helpful exercise prior to the pilot study as some significant suggestions were made which called for several modifications. Secondly, a follow-up pilot study initiative involved 
a sample of studentsfrom JUC, JIC, and JTI. This pilot study sample comprised 25 students, with a return rate of $100 \%$. The responses from this pilot sample did not request any further modifications to the instrument.

The population for this study comprised of 6884registered students in the affiliate Institutions of the Royal Commission in Jubail. While the random sample comprised of 1032 studentsrepresenting $15 \%$ of the population.

When an instrument is accurate and consistent, it is supposed to have a high degree of reliability [27]. According to a Cronbach Alpha, reliability for the used instrument was $88.98 \%$ for pilot data, while it was $91.6 \%$ for the instrument collected data, which reflects an acceptable levels of reliability for the survey instrument.

The instrument was designed to collect information relevant to experiences, use, and judgement aspects of ICTs. The ideas for instrument that was used in the study adopted and modified from the literature reviews of previous studies $[15,28,29,30]$.

Minges presented some of the common models and frameworks for assessing e-readiness [31]. The "World Economic Forum NRI" model is one of these models, which comprises three components: environment readiness, readiness to access ICTs, and ICTs use. For the purposes of this study, it is worth mentioning that the NRI is much closer to the current study objectives as it focuses of ICTs access and use. Thus, this study uses a modified NRI framework which is the most widely used in HEIs for assessing e-readiness compared to other models [32, 33].

Each one of the four constructs in the instrument had an accompanying measures/scales as follows:

1. Demographic information: This construct collects information regarding studying institution, age, gender, studying department, accessibility to computer and internet at office and at home, and finally training hours received related to using ICT for education purposes.

2. Experience with ICTs: 5-point Likert-type Scale as follows: 1 for "No Experience", 2 for "Below Average Experience", 3 for "Average Experience", 4 for "Above Average Experience", and 5 for "Expert".

3. Use of ICTs in studying and learning: 5-point Likert-Type Scale starts from 1 for "never", 2 for "rarely", 3 for "occasionally", 4 for "frequently", and 5 for "always".

4. Judgement about ICTs usein studying and learning: the scale asks participants to place an "X" at the point on the scale that agrees with his/her best judgment about the use of ICTs in his/her in studying and learning on a five point scale. The scale is categorized by several bi-polar adjectives.

Statistical Package for Social Science (SPSS) program version 19 used in coding and analysing data. The probability level for a test of statistical significance for the study is $\mathrm{p}<.05$, to ensure a $95 \%$ confidence in generalization of the findings. 
International Journal of Advanced Information Technology (IJAIT) Vol. 8, No.4/5, October 2018

\section{ANAlysis AND ReSUlts}

The test of normality of questionnaire data (PP plot), reliability test (Cronbach alpha), descriptive analysis, T-test, one-way analysis of variance (ANOVA), correlation analysis,

regression analysis, and univariate analysis of variance (F-test) were used in analysing both pilot and the collected data. The descriptive analysis was employed in order to determine the

frequencies, means, and standard deviations for dependent and independent variables. The T-test was employed in order to determine if means of two sets of scores are significantly different from each other or not. One-way ANOVA was employed in order to determine whether several sets of scores have different means or not. The correlation and multiple regression analysis was employed in order to determine the relationships among dependent and independent variables. The correlation was also used with piloted data in order to ensure the criterion and construct validity. The univariate analysis of variance was employed in order to see whether changes in the independent variables have significant effects on the dependent variable, and to discover interactions among independent variables and associations between dependent variables, if any. Cronbach alpha was used with both the piloted and the final version of the instrument in order to ensure that the instrument is reliable. A test of normality was conducted at the beginning in order to determine whether random variables were normally distributed or not, since this enhances the application of statistical tests applicable to normal distribution variables. The probability level for all tests of statistical significance for the study was set at $\mathrm{p}<0.05$. Highest level of education, studying institution and studyingdepartment were treated as categorical variables.

\subsection{ANALYSIS OF DEMOGRAPHIC INFORMATION}

Demographic information collected includes studying institution, gender, age, studying department, accessibility to computer and internet at HEIs and at home, and finally, training hours received related to using ICTs for education purposes.

Participants' demographics were tabulated by frequency and percentage as follows:

- Studying institution: Four hundred fifty six (44.2\%) respondents from JUC, four hundred thirty seven (42.3\%) respondents from JIC, and the remaining $136(13.5 \%)$ are respondents from JTI.

- Gender: Seven hundred ninety (76.6\%) are male students in the participating HEIs, while the remaining Two hundred forty two $(23.4 \%)$ respondents are females.

- Age: Participants' ages ranged from 15 to over 25 years old. The findings revealed that $32.1 \%$ of the respondents were between 15 and 20 years old (331 students). The respondents in the 20 to 25 age categories represented $66.7 \%$ (688 students), while the remaining respondents who were over 25 years old represented $1.3 \%$ (13 students).

- Studying departments: The findings revealed that $315(30.5 \%)$ of the respondents belong to Engineering departments. Two hundred forty nine (28.5\%) belong to Prep-year (basic skills) department. Forty (3.9\%) belong to English department. Thirty six (3.5\%) belong to Interior Design department. Seventy two (7\%) belong to Computer Science/Information Technology department. Sixty four (6.2\%) belong to Business Administration department. Twenty nine (2.8\%) belong to Accounting department. Eighteen (1.7\%) belong to Office Management 
International Journal of Advanced Information Technology (IJAIT) Vol. 8, No.4/5, October 2018

department. Fourteen (1.4\%) belong to Marketing department. Seventy five (7.3\%) belong to Management Information Systems department. The remaining 120 belongs to various technical industrial majors $(11.6 \%)$.

- Having accessibility to computer at home: 810 (78.5\%) respondents reported that they access computers at home, while $222(21.5 \%)$ respondents reported that they don't access computers at home.

- Having accessibility to computer at studying institution: 597 (57.8\%) respondents reported that they access computers at studying institution, while 435 (42.2\%) respondents reported that they don't access computers at studying institution.

- Having accessibility to internet at home: 861 (83.4\%) respondents reported that they access internet at home, while $171(16.6 \%)$ respondents reported that they don't access internet at home.

- Having accessibility to internet at studying institution: 662 (64.1\%) respondents reported that they access internet at studying institution, while 370 (35.9\%) respondents reported that they don't access internet at studying institution.

- Attended any course or workshop related to using ICTs in studying and learning: 229 (22.2\%) respondents reported that they attended course and/or workshop related to using ICTs in studying and learning, while $803(77.8 \%)$ respondents reported that they didn't attended any course and/or workshop related to using ICTs in studying and learning.

The relationship between students' demographics and demographics correlation with other questionnaire constructs examined using t-test, one-way ANOVA, and correlation.One-way analysis of variance (ANOVA) revealed that there is a significant difference between the use of ICTs in studying and learningwith each of the following:

- Studying institution (sig. $=0.011$ ),

- Studying department (sig. $=0.013)$,

- Age (sig. =0.017), and

- Attending any course or workshop related to using ICTs in studying and learning(sig. = $0.009)$.

In order to determine the "significant differences" between male and female students and their general use of ICTs, t-test was used. The mean extent of ICTs use in general for male $(n=790)$ respondents and female $(n=242)$ respondents shows that there is no significant difference between the responses of male and female. On the other hand, ANOVA revealed that there is no significant difference between the use of ICTs in studying and learning and each of the following:

- Gender (sig. = 0.129),

- Accessibility to computer at office (sig. $=0.106$ ),

- Accessibility to computer at home (sig. $=0.191)$,

- Accessibility to internet at office (sig. $=0.146)$, and

- Accessibility to internet at home (sig. $=0.103$ ).

Correlation coefficient between demographic variables revealed that attending any course or workshop related to using ICTs in studying and learning have a significant high positive correlation with the complete set of demographic variables. 
International Journal of Advanced Information Technology (IJAIT) Vol. 8, No.4/5, October 2018

\section{2 . EXPERIENCES WITH ICTS}

The general question on the experience with ICTs was introduced to respondents in the instrument after asking for information about their experience with different ICTs in their studying and learningin order to investigate their familiarity with ICTs. Data results for this question reveal a skewed result toward high positive experience levels

In response to the question about the experience with ICTs in studying and learning, the data reveals that, 405 of 1032 (39.2\%) respondents reported "Expert" with ICTs in their studying and learning. 331 (32.1\%) reported that they had "above average experience", 222 (21.5\%) reported that they had "average experience", 61 (5.9\%) reported that they had "below average experience", and $13(1.3 \%)$ reported that they had "no experience" with ICTs in their studying and learning.

The experience with the item "Computer use in general" had the highest level mean score, followed by the experience with "web searching", followed by the experience with "web browsers", followed by the experience with "Microsoft office", followed by the experience with "operating systems", followed by "e-mail", followed by the experience with "Blackboard", followed by the experience with "smart devices", and finally followed by with the least mean score was for the experience with "e-bulletin boards".

\subsection{USE OF ICTS IN STUDYING \& LEARNING}

The general question on the use of ICTs was introduced to respondents in the instrument after asking for information about their use of different ICTs in their studying and learningin order to investigate their various use degrees of ICTs. The data results for this question reveal a skewed result toward high positive use degrees.

In response to the question about the use of ICTs in studying and learning, the data reveals that, 392 of 1032 (38\%) respondents reported "always" using ICTs in their studying and learning. 381 $(36.9 \%)$ reported "frequently", 203 (19.7\%) reported "occasionally", 44 (4.3\%) reported "rarely", and $12(1.2 \%)$ reported "never" as their use degrees of ICTs in studying and learning.

The use of the item "Internet" had the highest level mean score, then the use of "smart devices", then the use of "presentation s/w", then the use of "e-mail", then the use of "e-materials", and finally the least mean score was for the use of "e-bulletin boards".

\subsection{Judgment About ICTS USE}

The judgement of students regarding the use of ICTs in their studying and learningis measured using a scale categorized by several bi-polar adjectives. There is a greatly skewed positive distribution in the opinions of the students'response regarding their judgement about using ICTs as 929 of 1032 regarded it as good (90\%), interesting (83.9\%), encouraging (86.4\%), meaningful $(89.4 \%)$, and exciting $(82.7 \%)$.

The analysis of questionnaire's data showed that the overall judgement of students towards ICTs is positive $(\mathrm{M}=5.62, \mathrm{SD}=0.88)$. In order to discover whether students'experience with ICTs is a predictor for their judgement about ICTs use, a multiple regression was conducted. The analysis 
International Journal of Advanced Information Technology (IJAIT) Vol. 8, No.4/5, October 2018

showed that the experience with ICTs did not significantly predict students'judgement about ICTs use (R $2=0.242$, adjusted $\mathrm{R} 2=0.061, \mathrm{~F}=1.451, \mathrm{p}=0.193)$.

This result is consistent with $[15,30,34,35,36,37]$ who found that students have a positive judgement about ICTs use in their case studies.

\section{CONCLUSION}

The current study assessed e-readiness of students in the affiliate institutions of the Royal Commission in Jubail through the investigation of their experiences, use, and judgement regarding ICTs. Also, it investigates whether students'experience in using ICTs influences their judgement regarding ICTs or not. That result provides valuable insights into students'e-readiness, as this information may be used to develop and support factors that effectively enhance future strategies for ICTs adoption to meet current and future needs.

It was discovered that the following set of ICTs requires the most attention in the future adoption planning by the Royal Commission for its three affiliate HEIs: "Blackboard", "smart devices", "e-bulletin boards", and "e-materials". This set of ICTs receives the least scores of use and experience responses from study participants. Future adoption of these set of ICTs will not be a difficult mission as the overall results showed a positive students' judgement about ICTs use, which reflect e-readiness and willingness to use ICTs.

The result of this study provides valuable insights into students' e-readiness. This information may be used to develop and support factors that enhance strategies for adopting ICTs by students. The critical analysis of the students' technological skills deemed extremely important in the evaluation of the current status of their e-readiness in Kingdom of Saudi Arabia, and it will help in strengthening themselves to apply ICTs effectively to meet education industry needs. Moreover, the value of investigating e-readiness is that it will enable policy-makers to prioritize interventions needed for transforming the Institutions of the Royal Commission of Jubail into an e-ready entity favorably placed to benefit from digital opportunities by suggesting enhancement ideas.

\section{SigNifiCANCE OF RESEARCH}

The current study has yielded information on e-readiness of students by investigating their experiences, uses, and judgments about ICTs in teaching, therefore adding to the limited literature on ICTs in HEIs in the Kingdom of Saudi Arabia context. This up-to-date information is very significant to administrators of HEIs in the Kingdom of Saudi Arabia.

The results represent positive encouragement for students to use ICTs in studying and learning. Moreover, the adopted survey instrument, which best suits the Kingdom of Saudi Arabia context and hence reflects the local students' characteristics, is more appropriate for use by researchers in the Kingdom of Saudi Arabia when investigating issues related to ICTs in HEIs, as this instrument does have its own statistical measures of reliability and validity. 
International Journal of Advanced Information Technology (IJAIT) Vol. 8, No.4/5, October 2018

\section{FUtURE RESEARCH}

The current research attempts to utilize a theoretical approach in an exploratory research area in order to reveal some findings. The following suggestions are recommended for future research studies based on these findings: (1) further research is necessary to address the limitations of the current study, since the research is limited only to a set group of available technologies within the domain of studying and learning in HEIs, it is highly recommended that further studies are conducted to adopt other sets of technologies, (2) further research is also recommended to include more case studies and to test other settings with other types of ICTs within other domains. These recommendations will enhance the generalizability of current research findings and will add more validity and reliability.

\section{REFERENCES}

[1] Manyika J, Chui M, Bughin J, Dobbs R, Bisson P, \&Marrs A., (2013) "Disruptive technologies: advances that will transform life business and the global economy". Retrieved August 2, 2017 from:www.mckinsey.com/insights/business_technology/disruptive_technologies.

[2] Lou E, \& Goulding J., (2010) "The pervasiveness of e-readiness in global built environment arena", Journal of Systems and Information Technology", Vol. 12, No. 3, pp 180-195.

[3] Rezaei, N.; Noornejad, S. (2016). An assessment on preparedness of students of Hamadan University of Medical Sciences in terms of participation in electronic learning system. International Journal of Humanities and Cultural Studies, January, pp. 1144-1151.

[4] Shin J, \& Harman G., (2009) "New challenges for higher education: global and Asia-Pacific perspectives", Asia Pacific Education Review, Vol. 10, No. 1, pp 1-13.

[5] Ozdemir Z, \&Abrevaya J., (2007) "Adoption of technology-mediated distance education: a longitudinal analysis", Information and Management, Vol. 44, No. 5, pp 467-477.

[6] Advisory Committee for Online Learning (2001) The E -learning e-revolution in colleges and universities, Executive Summary - A Pan-Canadian Challenge.

[7] Dikshit J, Gaba A, Bhushan S, Garg S, \& Panda S., (2003) "Learning Attitude, Motivation and Preferences of Online Learners", Indian journal of Open Learning, Vol. 12, No. 3, pp 149-167.

[8] Rohfeld R, \&Hiemstra R., (1995) "Moderating discussions in the electronic classroom", Computer mediated communication and the online classroom, Cresskill NJ: Hampton Press, Vol. 3, pp 91-104.

[9] Moolman H, \&Blignaut S., (2008) "Get set! e-Ready, e-Learn! The e-readiness of warehouse workers", Educational Technology and Society, Vol. 11, No. 1, pp 168-182.

[10] De Moraes M, Melo F, Oliver E, \& Cabral A., (2010) "Analysis of technological innovation strategy for small and medium companies of the aeronautical sector", Journal of Aerospace Technology Management, Vol. 2, no. 2, pp 225-236.

[11] Rohayani A, \&Sharipuddin K., (2015) "A literature review: readiness factors to measuring e-learning readiness in higher education", Procedia Computer Science, Vol. 59, No. 1, pp 230-234.

[12] Kumpulainen K., (2007) Educational Technology: Opportunities and Challenges, Oulu University Press, Oulu.

[13] Kakoty S, Lal M, \& Sarma S., (2011) "E-learning as a Research Area: An Analytical Approach", (IJACSA) International Journal of Advanced Computer Science and Applications, Vol. 2, No. 9, pp 13-20.

[14] Kakoty S, \& Sarma S., (2011) "Expert System Applications in E-learning Environment: Analysis on Current Trends and Future Prospects", International Journal of Internet Computing (IJIC), Vol. 1, pp 90-93. 
International Journal of Advanced Information Technology (IJAIT) Vol. 8, No.4/5, October 2018

[15] Elsaadani, M.; Alzahrani, S. 2018. Higher education faculty staff e-readiness in institutions of the Royal Commission in Jubail. International Journal of Advanced Information Technology (IJAIT), 8(3), pp. 1-14.

[16] Al-Busaidi K., (2013) "An empirical investigation linking learners' adoption of blended learning to their intention of full e-learning", Behavior \& Information Technology, Vol. 32, No. 11, pp 11681176

[17] Tubaishat A, \&Lansari A., (2011) "Are Students Ready to Adopt E -Learning? A Preliminary Ereadiness Study of a University in the Gulf Region", International Journal of Information and Communication Technology Research, Vol. 1, No. 5, pp 210-215.

[18] Marquardt M, \&Kearsley G., (1999) Technology-based learning: Managing human performance and corporate success, Boca Raton, Florida: St. Lucie Press.

[19] Goyal E, \&Purohit S., (2010) "Study of Using Learning Management System in a Management Course", SIESJournal of Management, Vol. 6, No. 2, pp 11-20.

[20] Islam A., (2012) Understanding e-learning system users' post-adoption usage behavior and its outcomes: a study of a learning management system, PhD Dissertation, Turku School of Economics, Turku.

[21] Ngampornchai, A.; Adams, J. (2016). Students' acceptance and readiness for E-learning in Northeastern Thailand. International Journal of Educational Technology in Higher Education, 1, pp. $13: 34$.

[22] Folorunso, O., Ogunseye, O. S., \& Sharma, S. K. (2006). An exploratory study of the critical factors affecting the acceptability of e-learning in Nigerian universities. Information Management \& Computer Security, 14(5), 496-505.

[23] Iqbal, M. J., \& Ahmad, M. (2010). Enhancing quality of education through e-learning: The case study of Allama Iqbal Open University. Turkish Online Journal of Distance Education, 11, 84-97.

[24] Addah, J. (2012). Computer literacy and E-learning: Attitudes among first year students in a Ghanaian medical school. International Journal of Computer Applications, 51, 22.

[25] Bediang, G., Stoll, B., Geissbuhler, A., Klohn, A., Stuckelberger, A., Nko’o, S., \&Chastonay, P. (2013). Computer literacy and E-learning perception in Cameroon: the case of Yaounde Faculty of Medicine and Biomedical Sciences. BMC Medical Education, 13, 57.

[26] Akhu-Zaheya, L. M., Khater, W., Nasar, M., \&Khraisat, O. (2011). Baccalaureate nursing students' anxiety related computer literacry: a sample from Jordan. Journal of Research in Nursing, 18(1), 3648.

[27] Mueller D., (1986) Measuring social attitudes: A handbook for researchers and practitioners. New York: Teachers College Press.

[28] Alharbi Y., (2002) A study of the barriers and attitudes of faculty and administrators toward implementation of online courses, Saudi Arabia (Doctoral dissertation, University of Northern Colorado, 2002), UMI Microform No. 3059974.

[29] Chen L., (2003) A study of how selected faculty and teaching staff members integrate web-based instruction in regular teaching, Unpublished doctoral dissertation, University of South Carolina.

[30] Alsaif A., (2005) The motivating and inhibiting factors affecting the use of webbased instruction at the University of Qassim in Saudi Arabia (Doctoral dissertation, Wayne State University, 2005), UMI Microform No. 3168482.

[31] Minges M., (2005) "Evaluation of e-readiness indices in Latin America and the Caribbean", Retrieved 10 August 2017 from: www.cepal.org/socinfo/publicaciones/xml/8/24228/w73.pdf

[32] Olatokun W, \&Opesade O., (2008) "An e-readiness assessment of Nigeria's Premier University (part 1)", International Journal of Education and Development Using Information and Communication Technology, Vol. 4, No. 2, pp 16-46.

[33] Tarvid A., (2008) "Measuring the e-readiness of higher education institutions", SSE Riga Student Research Papers, Vol. 6, pp 102, Stockholm School of Economics in Riga, Riga.

[34] Alghonaim H., (2005) Attitudes, barriers and incentives of Saudi college instructors and administrators toward implementation of online instruction (Doctoral dissertation, University of Kansas, 2005), UMI Microform No. 3185123. 
International Journal of Advanced Information Technology (IJAIT) Vol. 8, No.4/5, October 2018

[35] Ikpe, I. B. (2011). E-learning platforms and humanities education: An African Case Study. International Journal of Humanities and Arts Computing, 5(1), 83-101.

[36] Alzahrani S., (2012) "Assessment of learning at Jubail University College (JUC) using Information Technology (IT)", 5th International Conference of Education, Research and Innovation, November 19th - 21st, Madrid, Spain.

[37] Elsaadani M., (2014) "Business faculty e-readiness and willingness towards online instruction", World Journal on Educational Technology, Vol. 6, No. 2, pp 151-157.

\section{AUTHORS}

Dr. Saleh Alzahrani,As an assistant professor of Computer Science at Jubail University College, Dr. Alzahrani obtained his PhD degree from De Montfort University - UK in 2010. He has several research papers published internationally. Dr. Alzahrani currently occupies the post of the Academic Deputy at Jubail University College. He has a diverse profile with almost 25 years' experience in teaching/instructing, program developing, academic coordination, and as a senior executive in a the kingdom of Saudi Arabia.

Dr. Mohamed Elsaadani,As an assistant professor of Management Information Systems at Jubail University College, Dr. Elsaadani obtained his $\mathrm{PhD}$ degree from University of the West of England - UK in 2010. He has several research papers, as well as nationally and internationally published books in the field of IS and ICTs. Dr. Elsaadani is a professional consultant and human development trainer in the wide field of Business. He has a diverse profile with almost 24 years' experience in teaching/instructing, program developing, academic coordination, and as a senior executive in a multinational academic organizations in Egypt, Kingdom of Bahrain, and the kingdom of Saudi Arabia. Moreover, his wide experience is shared among both enterprises and academia.
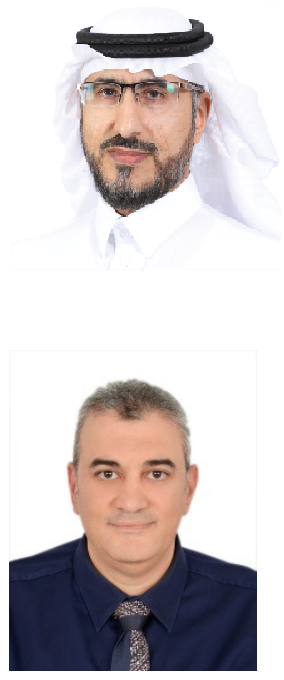
International Journal of Advanced Information Technology (IJAIT) Vol. 8, No.4/5, October 2018

INTENATIONAL BLANK 